\title{
PEMERTAHANAN BAHASA SUNDA DALAM UPACARA PERNIKAHAN TRADISIONAL DI KABUPATEN BANDUNG
}

\section{MAINTAINING THE USE OF SUNDANESE LANGUAGE IN TRADITIONAL WED- DING CEREMONY IN BANDUNG REGENCY}

\author{
Wagiati, Nani Darmayanti \\ Fakultas IImu Budaya, Universitas Padjadjaran \\ Jl. Raya Bandung Sumedang No.KM 21, Jatinangor, Kabupaten Sumedang \\ E-mail: wagiati@unpad.ac.id \\ E-mail: n.darmayanti@unpad.ac.id \\ Duddy Zein \\ Fakultas Ilmu Komunikasi, Universitas Padjadjaran \\ JI. Raya Bandung Sumedang No.KM 21, Jatinangor, Kabupaten Sumedang \\ E-mail: zein@unpad.ac.id
}

Naskah diterima tanggal: 15-11-2018, disetujui tanggal: 25-11-2018

\begin{abstract}
The aim of this research is to find out the methods for maintaining the use of Sundanese language in the Sundanese Traditional Wedding Ceremony in Bandung Regency, and to describe the factors that influence them. The method used in this reasearch was a descriptive-qualitative method. The data sources were the Sundanese traditional wedding ceremony in Kabupaten Bandung. The results show that the methods for maintaining the use of Sundanese language in the Sundanese traditional wedding Ceremony in Kabupaten Bandung include the traditional welcoming ceremony for bride and groom by lengser, saweran, ngaleupaskeun japati, door opening, and sungkem. The factors that influence the insistence of maintaining the usage of Sundanese language in the Sundanese Traditional Wedding Ceremony are to preserve the cultural identity and the cultural background of the bride and groom's family.
\end{abstract}

Keywords: Language maintenance, wedding ceremony, Sundanese language

Abstrak: Tujuan penelitian ini adalah mendeskripsikan bentuk-bentuk pemertahanan bahasa Sunda dalam upacara pernikahan adat Sunda di Kabupaten Bandung dan menjelaskan faktor-faktor yang mempengaruhinya. Metode yang digunakan adalah metode kualitatifdeskriptif. Sumber datanya adalah upacara pernikahan adat Sunda di Kabupaten Bandung. Berdasarkan data tersebut dilakukan analisis terhadapnya. Hasil penelitian menunjukkan bahwa bentuk pemertahanan bahasa Sunda pada upacara pernikahan adat Sunda di Kabupaten Bandung, Jawa Barat meliputi bentuk penjemputan oleh lengser, saweran inti, ngaleupaskeun japati, buka pintu, dan sungkem. Faktor yang menyebabkan terjadinya pemertahanan bahasa Sunda pada upacara pernikahan adat Sunda adalah mempertahankan identitas kultural dan latar belakang kultural keluarga yang melangsungkan upacara pernikahan tersebut.

Kata Kunci: Pemertahanan bahasa, upacara pernikahan, bahasa sunda

\section{PENDAHULUAN}

Situasi budaya suatu masyarakat guyub memiliki kaitan yang cukup erat dengan kondisi bahasa yang ada di dalamnya. Bahasa dan budaya saling berhubungan, dan hubungan di antara keduanya bersifat dinamis dan saling memengaruhi. Bahasa merupakan bagian dari kebudayaan, selain keberadaannya sebagai alat 
dan instrumen kebudayaan itu sendiri. Dalam kaitannya dengan kondisi demikian, untuk memahami suatu kebudayaan guyub tertentu berarti mesti memahami bahasanya (Duranti, 1997).

Seperti halnya bahasa secara global, bahasa daerah juga memiliki posisi yang sama dengan bahasa pada umumnya. Keberadaannya merupakan bagian integral yang tidak dapat dipisahkan dari kebudayaan lokal suatu masyarakat tertentu. Bahasa daerah, dalam relasi kultural tersebut, dapat dimaknai sebagai bagian dari instrumen sosial dan praktik budaya lokal. Secara implisit, budaya daerah ataupun budaya lokal merupakan salah satu bentuk ekspresi pemikiran tentang kondisi dan keadaan masyarakat setempat. Bahasa daerah juga dapat dipandang sebagai suatu sistem ilmu pengetahuan yang di dalamnya terdapat nilai yang dimiliki oleh masyarakat yang memengaruhi perilaku masyarakat itu sendiri (Aritonang, 2017).

Nilai-nilai yang terkandung dalam budaya lokal sekaligus sebagai jiwa dari budaya lokal. Hal tersebut menjadi dasar dari segala wujud kebudayaan daerah. Adanya regenerasi dan pewarisan budaya dari generasi tua kepada generasi muda menjadi hal yang sangat penting. Di dalam masyarakat, hal tersebut menjadi keberlangsungan budaya lokal.

Budaya lokal yang beraneka ragam merupakan warisan budaya yang wajib untuk dijaga dan dilestarikan keberadaannya. Bangsa lain yang memiliki sedikit budaya lokal terus bekerja keras menjaga dan melestarikannya sebagai bentuk identitas kulturalnya. Sungguh naif jika yang dikaruniai banyak budaya lokal lantas mengabaikan proses pelestarian dan regenerasinya itu. Bentuk-bentuk budaya lokal yang ada dan berkembang pada suatu daerah, misalnya, cerita rakyat (dongeng), ritual tradisional, tradisi kedaerahan, seni dan kreativitas (seni tari, lagu, dan kesenian daerah), dan keunikan masyarakat setempat.
Dengan mengenal bentuk seni tradisi Sunda diharapkan generasi muda lebih mengenal jati diri dan menghargai nilai-nilai budaya sendiri (Dwimarwati, 2013).

Dalam kaitannya dengan kekayaan intelektual, kearifan lokal sebagai bagian dari kebudayaan masyarakat setempat, perlu terus dijaga dan dipertahankan. Spradley (2016) mengemukakan bahwa kebudayaan merupakan pengetahuan yang diperoleh dan digunakan oleh manusia untuk menginterpretasi pengalaman dan melahirkan tingkah laku sosial tertentu. Dengan demikian, keberadaannya mesti terus berlangsung dari satu generasi kepada generasi selanjutnya karena budaya lokal berfungsi sebagai penyebar nilai-nilai kultural dari satu generasi kepada generasi lainnya. Instrumen utama yang digunakan untuk menyebarkan nilainilai kebudayaan lokal adalah dengan melalui bahasa daerah.

Dalam kaitannya dengan kehidupan sosial dalam masyarakat suatu daerah, bahasa daerah memiliki dua fungsi utama, yaitu sebagai alat komunikasi dan sebagai pengantar kegiatan upacara tradisional. Halliday (1973) mengemukakan tentang fungsi bahasa dalam kehidupan sosial, yaitu fungsi pragmatik dan fungsi ritual. Penggunaan bahasa dalam ranah ritual dapat dipahami sebagai wacana berbahasa di dalam lingkungan kegiatan ritual yang ada di suatu masyarakat tertentu. Dalam kaitannya dengan regenerasi dan keberlangsungan budaya lokal dan nasional, tugas dan kewajibannya ada pada pemerintah dan seluruh bangsa Indonesia (Purnomowulan, Samson, Machdalena, Dewi,\& Endrawan, 2017).

Bahasa sangat erat kaitannya dengan kondisi sosio-kultural masyarakat penuturnya. Oleh sebab itu, manifestasi bahasa sangat dipengaruhi oleh latar belakang budaya dari masyarakat penutur bahasa tersebut. Selain itu, bahasa juga menjadi unsur sangat penting dalam kehidupan budaya suatu kelompok masyarakat tertentu. Pastika (2012) mengemukakan bahwa 
bahasa memiliki peran yang sangat dominan dalam kehidupan manusia karena bahasa tidak hanya menjadi bagian dari kebudayaan manusia, tetapi juga menjadi faktor penentu perkembangan budaya kelompok masyarakat tersebut. Oleh karena itu, dalam konteks sosiokultural, bahasa sangat identik dengan dinamika sosial masyarakat penuturnya (Brata, 2010).

Penggunaan dan pemakaian bahasa tidak hanya ditentukan oleh faktor linguistik tetapi juga juga oleh faktor-faktor nonlinguistik. Faktor nonlinguistik berkenaan dengan hal-hal yang berada di luar bahasa itu sendiri. Tetapi memiliki kaitan dan hubungan yang sangat erat dengan faktor sosial dan situasional. Rokhman (2013) mengemukakan bahwa praktik berbahasa dipengaruhi oleh sosial-kultural dan situasional. Satu di antara dampak dari adanya kedua faktor tersebut adalah munculnya variasi-variasi bahasa yang berwujud pola-pola lingual yang menyerupai pola umum dari bahasa-bahasa induknya (Poedjosoedarmo, 2017).

Melihat realitas lingual yang ada tersebut, dapat dipahami bahwa penggunaan bahasa dalam suatu masyarakat tutur tidaklah bersifat monolitis melainkan memiliki varian dan polapola yang variatif. Karena faktor tersebut maka dalam satu masyarakat tutur tertentu hampir tidak ada satu penutur bahasa pun yang monolingual. Para penutur bahasa biasanya akan memiliki kompetensi berbahasa lebih dari satu bahasa, sehingga memunculkan masyarakat bilingual atau bahkan multilingual yang akan berdampak pula pada adanya kontakkontak bahasa. Hal ini tentu akan terjadi pada suatu masyarakat tutur yang bilingual atau multilingual. Saling kontak antarbahasa ini akan terjadi dalam konteks sosial tertentu, yakni suatu kondisi ketika seseorang sedang mempelajari bahasa kedua dalam masyarakat tutur tersebut. Adapun bilingualisme itu sendiri dapat dipahami sebagai suatu kondisi ketika dua bahasa atau lebih digunakan oleh seorang penutur dalam situasi tutur yang bersamaan.
Jika diamati lebih mendalam, dapat dipahami bahwa gejala kontak bahasa lebih cenderung pada gejala bahasa (language). Adapun bilingualisme lebih cenderung kepada gejala tutur (parole). Oleh sebab itu, gejala bilingualisme merupakan dampak dari adanya kontak bahasa dalam suatu masyarakat tutur tertentu.

Penggunaan bahasa, khususnya bahasa daerah Sunda, dalam proses ritual tradisional merupakan bagian dari kebudayaan yang masih hidup dan berkembang pada masyarakat pendukungnya. Di dalamnya terdapat struktur linguistik dan bentuk-bentuk makna simbolik yang merepresentasikan kelompok sosial tertentu. Oleh karena itu, penggunaan bahasa dalam aktivitas guyub tertentu menjadi bagian utuh yang tidak terpisahkan dari budaya masyarakat setempat. Penggunaan unsur-unsur linguistik dianggap oleh ahli antropolinguistik sebagai fitur penting yang mampu merepresentasikan kelompok masyarakat atau kelas sosial tertentu (Duranti, 1997).

Bahasa Sunda sebagai bahasa ibu masyarakat Sunda, sekaligus dijadikan sebagai alat komunikasi dalam kehidupan sehari-hari. Adanya politik bahasa yang menempatkan bahasa Indonesia sebagai bahasa nasional telah memengaruhi penggunaan bahasa-bahasa daerah, termasuk penggunaan bahasa Sunda. Itulah sebabnya, dewasa ini keberadan bahasa Sunda, seperti halnya bahasa-bahasa daerah lainnya, mulai mengalami tekanan fungsional seiring dengan politik bahasa tersebut. Atas fakta tersebut, dewasa ini dapat disaksikan bahwa bahasa Sunda mulai ditinggalkan oleh penuturnya, meskipun sama-sama berkomunikasi dengan penutur Sunda. Dengan demikian, disadari ataupun tidak, bahasa Sunda telah mengalami pergeseran bahasa. Bahkan jika kondisi ini terus dibiarkan, tidak menutup kemungkinan akan mengarah kepada gejala kepunahan bahasa (language death). Mbete (2015) berpendapat bahwa apabila dalam suatu 
keluarga, praktik berbahasa antara orang tua dengan anaknya dan sebaliknya dalam bahasa lokal sudah semakin jarang bahkan menghilang, kondisi ini merupakan tanda serius akan adanya kematian bahasa.

Meskipun demikian, penggunaan bahasa Sunda pada ranah-ranah tertentu tidak selamanya ditinggalkan oleh penuturnya. Realitas lingual menunjukkan bahwa, pada kelompok tutur tertentu, ada yang masih konsisten menggunakan bahasa Sunda sebagai alat komunikasinya. Beberapa situasi bahasa tersebut ada pada saat proses ritual tradisional tertentu, seperti proses ritual pernikahan tradisional di Kabupaten Bandung. Dalam pelaksanaannya, proses pernikahan tradisional di Kabupaten Bandung masih ada yang menggunakan bahasa Sunda sebagai bahasa pengantar untuk menyampaikan pesanpesannya, dalam bentuk tuturan, tembang, kidung, pantun, puisi, dan doa.

Artikel ini akan mengkaji pemertahanan bahasa Sunda dalam upacara pernikahan adat Sunda yang ada pada masyarakat Sunda, khususnya di Kabupaten Bandung. Dalam konteks regenerasi dan pelestarian budaya, pemertahanan bahasa Sunda dilakukan sebagai upaya mengobservasi bahasa daerah agar tetap eksis dan tidak mengalami pergeseran bahasa, atau bahkan kematian bahasa. Mengacu pada permasalahan di atas, terdapat dua tujuan utama yang diungkap pada penelitian ini, yaitu mendeskripsikan bentuk-bentuk pemertahanan bahasa Sunda dalam upacara pernikahan adat sunda di Kabupaten Bandung dan menjelaskan faktor-faktor sosio-kultural yang berpengaruh pada proses pemertahanan bahasa Sunda dalam upacara pernikahan adat Sunda di Kabupaten Bandung.

\section{METODE}

Penelitian ini dilakukan pada bulan April 2018 dan menggunakan pendekatan, yaitu teoretis dan metodologis. Secara teoretis, pendekatan yang digunakan dalam penelitian ini adalah pendekatan sosiolinguistik. Sosiolinguistik dipahami sebagai bidang interdisipliner antara sosiologi dan linguistik. Fokus utama pada penelitian ini adalah tentang pemertahanan bahasa. Pembahasan tentang pemertahanan bahasa tidak bisa lepas dari konsep atau pembicaraan tentang kekhawatiran akan adanya perubahan bahasa (language change), peralihan bahasa (language shift), dan kematian bahasa (language death). Dalam kajian ini, selain pembahasan mengenai pemertahanan bahasa Sunda, akan dipertimbangkan juga faktor-faktor sosio-kultural yang memengaruhi pemertahanan bahasa Sunda dalam proses upacara pernikahan adat Sunda di Kabupaten Bandung.

Secara umum, sosiolinguistik memandang gejala-gejala lingual sebagai realitas sosial yang erat hubungannya dengan pemakaian bahasa dalam konteks yang sesungguhnya (Rokhman, 2013). Dengan demikian, sosiolinguistik memandang gejala pemertahanan bahasa sebagai peristiwa tutur dalam konteks komunikasi yang menunjukkan adanya perwujudan identitas sosio-kultural anggota tutur. Atas dasar itu, secara teoretis, sosiolinguistik yang menjadi bahan kajian pada penelitian ini, difokuskan pada subkajian berupa etnografi komunikasi yang telah dikembangkan oleh Hymes (dalam Rokhman, 2013).

Penelitian ini akan bermanfaat secara teoretis dan praktis. Dalam hubungannya dengan manfaat teoretis, penelitian ini akan melengkapi ruang kosong dalam konteks kajian bahasa. Khusus pemertahanan bahasa akan didapatkan sebuah kajian pemertahanan bahasa yang lebih kompleks dan komprehensif. Adapun secara praktis, penelitian ini bisa dijadikan sebagai acuan strategis dalam proses pemertahanan bahasa dan pengembangan bahasa Sunda sebagai satu di antara bahasa daerah yang ada di Indonesia.

Pendekatan yang dipakai pada penelitian ini adalah pendekatan kualitatif-deskriptif. 
Secara kualitatif artinya data yang diteliti dan hasil analisisnya diperoleh dari rekaman, pengamatan, wawancara, atau bahan tertulis, dan data ini tidak berbentuk angka. Sementera itu, pendekatan deskriptif mendasarkan pada fakta, yang secara empiris diperoleh dari penutur-penuturnya sehingga hasilnya berupa uraian unsur-unsur bahasa seperti apa adanya.

Tahapan penelitian ini dibagi ke dalam tiga tahapan, yaitu tahap penyediaan data, tahap analisis data, dan tahap penyajian hasil analisis data. Sehubungan dengan hal tersebut, peneliti mengamati setiap praktik lingual yang ada pada upacara pernikahan adat Sunda di Kabupaten Bandung, dalam hal ini di Kecamatan Cicalengka. Pengamatan tersebut secara khusus dilakukan dengan menggunakan teknik sadap dan dilanjutkan dengan teknik turunan berupa teknik simak bebas libat cakap, teknik rekam, dan teknik catat (Sudaryanto, 2015). Metode dan teknik tersebut digunakan secara berkesinambungan, sistematis, dan komprehensif sehingga terjaring data yang bervariatif. Selain itu, digunakan teknik wawancara terstruktur untuk menjaring data sekunder berupa pengakuanpengakuan masyarakat tutur, agar terlihat alasan-alasan pemertahanan bahasa yang digunakan.

Adapun sumber data pada penelitian ini berupa ungkapan-ungkapan yang ada pada upacara pernikahan adat sunda. Ritual tersebut menjadi satu di antara ritual tradisional yang masih menggunakan bahasa Sunda sebagai medium penyampaian pesan. Dalam pelaksanaan penjaringan data, penelitian dilaksanakan di Kecamatan Cicalengka, Kabupaten Bandung. Penelitian ini dilakukan pada bulan Juli 2018 dengan mempertimbangkan ketersediaan pelaksanaan upacara pernikahan Sunda di Kecamatan Cicalengka tersebut.

Data-data yang terjaring melalui perekaman dan pencatatan di lapangan, ditranskripsikan, diklasifikasikan, dan ditafsirkan sementara. Hal tersebut untuk menjaga relevansi dan keabsahan data. Data yang terjaring dilakukan dengan beberapa cara berikut: 1) keikutsertaan langsung; 2) ketekunan pengamatan; 3) triangulasi, baik berupa triangulasi sumber data yang diperoleh melalui pengamatan dan wawancara, maupun triangulasi teoretis dan metodologis; dan 4) pemeriksaan kembali datadata yang sudah dijaring dari informan dan dikonsultasikan dengan rekanan yang memiliki kompetensi dengan topik penelitian ini (Muhadjir, 2011). Bagian dari upacara pernikahan adat Sunda yang akan dijadikan fokus utama penelitian ini adalah bagian yang mengandung unsur wacana, yaitu proses saweran. Proses saweran yang ada dalam upacara pernikahan adat Sunda memiliki rangkaian berupa: penjemputan oleh lengser, ngabageakeun (penyambutan), pemberian wejangan, saweran inti, nincak endog 'injak telur', ngalepaskeun japati 'melepaskan burung merpati', buka pintu, sungkem, meuleum harupat, huap lingkung, dan pabetot-betot bakakak.

Analisis data dilakukan dengan metode kualitatif. Kegiatan analisis yang dilakukan berkenaan dengan pola-pola umum pada wujud dan perilaku data yang ada. Data yang sudah dianalisis disajikan secara deskriptif. Perumusan dan pengungkapan hasil analisis dengan menggunakan kata-kata atau kalimat-kalimat. Analisis data dilakukan dengan prosedur berikut: 1) reduksi data (data reduction), yakni berupa pengidentifikasian pemertahanan bahasa; 2) penyajian data dengan matriks; dan 3) penarikan simpulan dan verifikasi yang sifatnya tentatif, baik dengan triangulasi data maupun dengan triangulasi metode dan teknik penjaringan data.

\section{HASIL DAN PEMBAHASAN Bentuk Pemertahanan Bahasa dalam Upacara Pernikahan Adat Sunda di Kabupaten Bandung}

Dalam realitas lingual, bahasa Sunda telah menjadi bahasa ibu bagi sebagian besar penutur 
bahasa di wilayah Jawa Barat. Dalam beberapa situasi tuturan dan beberapa ranah komunikasi, bahasa Sunda kini sudah tergantikan oleh bahasa Indonesia sebagai bahasa nasional. Meskipun demikian, pada situasi lainnya, bahasa Sunda masih digunakan sebagai alat komunikasi. Jika bahasa dikaitkan dengan ritual tradisional yang ada di wilayah Jawa Barat, khususnya Kabupaten Bandung, bahasa Sunda masih digunakan sebagai instrumen komunikasi dan media ekspresi ritual tradisional. Salah satu ritual tradisional yang masih menggunakan bahasa Sunda sebagai bahasa pengantarnya adalah upacara pernikahan adat Sunda di Kabupaten Bandung. Dalam penelitian ini, dikemukakan beberapa bentuk pemertahanan bahasa Sunda dalam upacara pernikahan adat Sunda. Bentukbentuk itu meliputi bagian penjemputan oleh lengser, saweran inti, ngaleupaskeun japati, buka pintu, dan sungkem.

\section{Penjemputan oleh Lengser}

Penjemputan oleh lengser merupakan bagian pertama dari rangkaian saweran dalam upacara pernikahan adat Sunda. Calon pengantin akan dijemput oleh seorang lelaki tua yang dinamakan lengser. Dalam pelaksanaan penjemputan, lengser akan menembangkan nasihat-nasihat untuk pasangan pengantin. Nasihat-nasihat tersebut juga ditujukan agar upacara pernikahan dapat berjalan dengan lancar. Proses penjemputan oleh lengser ini terdiri dari tiga bagian, yaitu lengser midang, prolog, dan nasihat lengser. Ketiga bagian dari proses penjemputan oleh lengser ini menggunakan bahasa Sunda sebagai ekspresi lingualnya.

\section{Data (1) \\ Lengser Midang}

Kuring rek midang, mangsa poe bengras

caang

Kuring rek midang, dangdan ti kamari

dangdan

Kuring rek midang, boga pancen ti jungjunan

Kuring unjukan, kudu ngalur karuyaan
Kuring rek midang, pikeun ngatur kariaan Kuring unjukan, boga pancen ti jungjunan Hayu urang papo, poe nu pinuh kabagjaan

Dalam Bahasa Indonesia:

\section{Keberangkatan Lengser}

Saya mau berangkat, saat hari sangat cerah Saya mau berangkat, berdandan dari kemarin Saya mau berangkat, karena tugas dari pimpinan

Saya mau menampilkan, dan mengatur perayaan

Saya mau berangkat, saat hari sangat cerah Saya mau berangkat, untuk mengatur perayaan

Saya mau menampilkan, karena tugas dari pimpinan

Mari kita jemput, hari yang penuh kebahagiaan

\section{Data (2) \\ Prolog}

Hadirin nu ku sim kuring dipihormat, Canduk waktu nu geus tangtu datang Mangsa nu utama nitih wanci nu mustari Manusa moal bisa ngahalang-halang, Aya mangsa datang aya mangsa mulang

Dalam bahasa Indonesia:

\section{Prolog}

Hadirin yang saya hormati, Waktu yang telah ditentukan

Masa yang utama dan pertama saat yang tepat Manusia tidak bisa menentukan

Kapan waktu yang tepat untuk datang dan pergi

\section{Data (3)}

\section{Nasehat Lengser}

Sujud syukur ka nu Agung

Ka Allah Rabbul Izzati

Wireh tos cunduk ka waktu

Ningang mangsa nu utama

Nitih wanci nu mustari

Laksana panesa ati

Acara pangjurung laku

Pangjajap rasa kemelang

Amit ampun nya paralun

Bilih manawa manawi 
Manawi ku teu katampi

Neda jembar hampurana

Geuning sumangga urang lajengkeun

Dalam bahas Indonesia:

\section{Nasihat Lengser}

Sujud syukur kepada Tuhan Yang Maha Esa

Kepada Allah yang Maha Kuasa

Karena sudah tiba waktunya

Datang masa yang utama

Pada saat yang tepat

Bagaikan permata hati

Acara pendorong jalan

Penghantar rasa was-was

Mohon maaf hadirin

Bila ada suatu hal

Yang mungkin tidak diterima

Mohon maaf yang sebesar-besarnya

Mari kita lanjutkan

Data (1) sampai dengan (3) merupakan penggalan dari acara penjemputan pengantin oleh lengser pada upacara pernikahan adat Sunda. Proses penjemputan pengantin oleh lengser ini terbagi menjadi tiga bagian utama, yaitu lengser midang 'keberangkatan lengser', prolog, dan nasihat lengser. Data (1) merupakan penggalan dari bagian lengser midang, data (2) merupakan penggalan dari prolog yang diucapkan oleh lengser, dan data (3) merupakan penggalan dari nasihat lengser.

Ketiga bagian dari proses penjemputan pengantin oleh lengser diungkapkan seluruhnya dalam bahasa Sunda, tanpa ada gejala campur kode dan alih kode dengan bahasa lainnya. Penggunaan bahasa Sunda dalam tuturan yang ada pada bagian penjemputan oleh lengser tersebut telah menampilkan adanya loyalitas berbahasa yang ditampilkan oleh lengser pernikahan. Dalam kaitannya dengan sosiolinguistik, realitas lingual yang ditampilkan oleh lengser dengan menggunakan bahasa Sunda telah menampilkan adanya sikap bahasa yang positif. Sikap bahasa yang ditampilkan oleh penutur atau kelompok tutur suatu bahasa tertentu akan menjadi faktor penentu gejala pe- mertahanan bahasa dan pergeseran bahasa. Oleh karena itu, lengser pernikahan yang memiliki sikap bahasa positif terhadap penggunaan bahasanya, akan membantu proses pemertahanan bahasa.

\section{Saweran}

Setelah pengantin dijemput oleh lengser, proses selanjutnya adalah saweran. Secara etimologi, nyawer memiliki makna menebar nasihat. Nasihat diberikan oleh kedua orangtua kepada anaknya yang akan menempuh hidup berumah tangga. Secara historis, pelaksanaan saweran pada zaman dulu dilakukan oleh kedua orangtua kandung dari kedua mempelai. Pada saat ini hal tersebut lebih sering dilakukan oleh tukang sawer karena tidak semua orang memiliki kemampuan melantunkan kidung-kidung sawer.

Sawer dilakukan dengan ungkapanungkapan puitis dan dilantunkan dengan tembang-tembang kidung. Kedua pengantin duduk di kursi dengan dinaungi payung. Pantun yang disampaikan oleh tukang sawer biasanya berisi tentang petuah-petuah hidup dari kedua orangtua kepada kedua mempelai. Setelah dinyanyikan tembang sawer, kedua orangtua pengantin akan menyawer pengantin dengan taburan biji-bijian (biasanya berupa kacang tanah dan jagung), beras kuning dan kunyit, beberapa macam bunga, uang logam, permen, dan perlengkapan makan sirih.

Berikut ini adalah beberapa tembang atau kidung sawer yang dinyanyikan oleh tukang sawer pada pernikahan adat Sunda.

\section{Data (4)}

\section{Sawer Panganten}

\section{Jemplang Karang (Asmarandana)}

1. Neda ageung panghaksami

mohon maaf sebesar-besarnya

Ka sadaya pamiarsa

pada semua pemirsa

Bade nyelang heula nyawer

meminta waktu hendak menyawer 
Etang-Etang ngiring bingah

sebagai rasa ikut bahagia

Ka anu nembean nikah

kepada pengantin yang baru menikah

Mugi-mugi lulus banglus

semoga berjalan lurus lancar

Tebih tina pacengkadan

jauh dari pertengkaran

2. Nitih wanci nu mustari

telah datang waktu yang tepat

Ningang mangsa nu utama

pada saat yang utama

Hidep duaan ngarendeng

kalian berdua duduk berdampingan

Sanggeus rengse dirapalan

setelah selesai dimohonkan doa

Kalayang Widi Pangeran

kepada Tuhan Yang Maha Kuasa

Di wengku tali usikun

karena ikatan tali perkawinan

Salamet geus dirapalan

yang sudah diucapkan saat akad

3. Jodo bareunang pribadi

mendapat jodoh karena keinginan pribadi

Lain kahayang nu lian

bukan keinginan orang lain

Lain amprok pareremo

bukan sembarang pertemuan

Estuning pokal sorangan

tapi sungguh kemauan sendiri

Beunang mupakat duaan

hasil kesepakatan berdua

Kajurung ku doa sepuh

didorong oleh doa orang tua

Teu hilap ti kadang warga

tak lupa juga dari sanak saudara

4. Eling-eling angina lirih

ingat angin bertiup perlahan

Nu nembak na lelembutan

bertiup dengan penuh kelembutan

Muga ngoyagkeun panganten semoga menyentuh hati pengantin

Ngoyagkeun sanubarina

menyentuh hati sanubarinya

Dumeh ayeuna waktuna

sekarang adalah waktunya

Ngitung-ngitung nu dipaju

menghitung waktu yang berjalan

Sabdana dirapalan

sekarang telah mengucapkan janji

Isi sawer yang dilantunkan tersebut berupa asmarandana. Asmarandana merupakan puisi atau tembang tradisional Sunda yang menggambarkan kehidupan atau pesan-pesan bijak.

Tembang atau kidung sawer yang dilantunkan oleh petugas sawer diungkapkan sepenuhnya dengan menggunakan bahasa Sunda. Penggunaan bahasa Sunda dalam tuturan yang ada pada bagian sawer telah menampilkan adanya loyalitas berbahasa yang ditampilkan oleh tukang sawer pada upacara pernikahan adat Sunda. Dalam konteks sosiolinguistik, realitas lingual yang ditampilkan oleh tukang sawer dengan menggunakan bahasa Sunda telah menampilkan adanya sikap bahasa yang positif.

\section{Ngalepaskeun Japati 'Melepaskan Burung Merpati'}

Dalam konteks kultural yang ada pada masyarakat Sunda, merpati dianggap sebagai binatang yang selalu hidup rukun berdampingan, jarang terjadi pertengkaran di antara mereka, apalagi saling mencakar. Dalam kaitannya dengan konteks kultural yang lebih luas, merpati dapat dipahami sebagai lambang pemberi kabar dan kejujuran.

Dalam kaitannya dengan upacara pernikahan adat Sunda merpati dikaitkan dengan simbol pemberi kabar. Kabar inilah yang ingin disampaikan oleh kedua keluarga yang melaksanakan pernikahan bahwa telah terjadi pernikahan dua insan yang telah sepakat untuk hidup berumah tangga. Bersama iringan doa, 
ibu pengantin pria melepaskan merpati jantan dan ibu pengantin wanita melepaskan merpati betina. Pelepasan burung merpati ini diawali dengan ucapan doa oleh ibu pengantin wanita. Karena tidak semua orang memiliki kemampuan melantunkan doa, maka diserahkan kepada juru sawer pernikahan. Berikut ini adalah contoh isi lantunan doa pada saat prosesi pelepasan burung merpati.

\section{Data (5)}

Nyai geulis anaking

anakku yang cantik, Pupunden Ema jeung Bapa

pujaan ibu dan bapak

Salapan bulan Ema ngakandung

9 bulan ibu mengandung

Dikukuntit ku karisi

dengan perasaan tidak tenang

Dirancana ku karempan

rasa was-was

Sieun kitu sieun kieu

takut ini dan itu

Kakandungan kuma onam

terjadi pada kandungan

Beurat burayang bureuyeung

kubawa kemana-mana

Eungap rumenghap rumahuh

walau terasa berat

Teu ieuh aral subaha

nafas sesak

Mapan dina panghareupan

supaya tidak ada aral melintang yang dihadapi

Nu dikandung mulus tur rahayu

dalam keadaan lahir

Geulis,

anakku,

Dua poe dua peuting

dua hari dua malam

Ema nandonkeun nyawa

ibu bertaruh nyawa

Rek ngalahirkeun nyai

untuk melahirkanmu

Teu daek brol tidak mau keluar

Pati Ema sasat guwang-gawing

nyawa terasa akan lepas

Ngagantung dina rambut salambar

bagai menggantung di sehelai rambut

Matak ketir baluas kadieunakeun

gelisah menghadapi kelahiranmu

Alhamdulillah

Alhamdulillah

Murahna Allah subhanahu wa taala

atas kemurahan Allah SWT

Putra Ema medal, salamet

anakku lahir dengan selamat

Dirorok didama-dama

dirawat dengan sepenuh kasih sayang

Dijaring diaping beurangna peutingna

kulindungi kudampingi siang malam

Ditanggeuy dieugueh-eugeuh

digendong, diayun

Diatik diwaris harti

bagai harta warisan tak ternilai

23 taun ayeuna (yuswa panganten istri)

23 tahun sudah umurmu

Cunduk dawuhna datang mangsana

muncul perintah datang waktunya

Wet kudu papisah

harus berpisah

Nalangsa galo jeung bungah

sedih bahagia bercampur

Teu panasaran

tidak ada rasa penasaran

Da aya nu neruskeun nyaah

Neruskeun bela

karena ada yang meneruskan

untuk mengasihi dan membelamu

Nya Kang Agus (jenengan panganten pameget)

Panutan nyai

yang menjadi teladanmu

Ema, Bapa, jumurung pisan

ibu bapak sangat bahagia

Suka lilah sadrah pisan

pergilah dalam keadaan takwa dan tawakal

Bral geura mencar

Tarawekal malotekar 
Lulus mulus sauyunan

dalam usaha yang mulus

Silih belaan duaan

bekerjasamalah saling membela

Silih asih silih asuh

mengasihi dan menghormati

Deudeuh silih pikanyaah

Lambat lambut runtut raut

Sayang, saling menyayangi

Jatnika lahir batin

bersatulah lahir batin

Rumengkap nepi ka pati

perlahan-lahan sampai mati

Cangreud dina sanubari

terikat dalam hati sanubari

Agem agama tatapakan

menjalankan perintah agama

Darigama panaggeuyna

sebagai pengikat perjalanan hidup

Enggoning hirup

Dalam kehidupan

Insyaa Allah rahmat salamet

Insyaa Allah berkat keselamatan

Bral anaking buah ati, beubeulahan nyawa

Anakku belahan hatiku... (melepas merpati dari sarang)

Perlambangna japati leupas tina kurung...

Seperti lepasnya burung merpati dari sangkar

Ya Allah nyanggakeun...

ya Allah, kuserahkan padamu...

(Muchtar, 1987)

Data (5) di atas merupakan bagian wacana yang dilantunkan oleh ibu pengantin wanita atau juru sawer pada rangkaian acara ngalepaskeun japati 'melepaskan merpati'. Wacana tersebut berupa pangeling 'pengingat' yang disampaikan oleh ibu pengantin wanita kepada anaknya tentang perjalanan hidup dan petuah kehidupan. Isi wacana yang ada pada rangkaian ngalepaskeun japati ini tidak jauh berbeda dengan prosesi saweran. Isi, konten, dan nilai yang disampaikan dari keduanya memiliki kesamaan. Jika diamati secara sosiolinguistik, realitas lingual yang ditampilkan oleh juru sawer pada rangkaian ngalepaskeun japati tersebut telah menampilkan sikap bahasa yang positif. Sikap bahasa ini, pada masanya akan berjalan beriringan dengan loyalitas bahasa. Pada pelantunan doa, seluruhnya menggunakan bahasa Sunda, tanpa ada campur kode dan alih kode dengan bahasa lainnya. Penggunaan bahasa Sunda dalam tuturan yang ada pada doa dalam rangkaian ngalepaskeun japati tersebut telah menampilkan adanya loyalitas berbahasa yang ditampilkan oleh juru sawer.

\section{Buka Pintu}

Rangkaian selanjutnya adalah "buka pintu". Prosesi ini memiliki makna bahwa setiap orang yang datang bertamu, harus memohon izin dahulu kepada si pemiliki rumah dengan mengetuk pintu dan mengucapkan salam. Sebelum memasuki rumah keluarga pengantin wanita, pengantin pria harus mengetuk pintu dahulu sebanyak tiga kali. Dari dalam rumah, si pengantin wanita tidak langsung membukakan pintu. Pengantin wanita harus memastikan dahulu apakah yang mengetuk pintu tersebut merupakan pria yang benar-benar akan menikahinya. Hal ini bermakna agar kita tidak sembarangan membukakan pintu untuk orang lain. Saat pengantin pria sudah membuka pintu dan melangkahkan kakinya memasuki rumah, pengantin wanita akan menyambutnya dengan munjungan, yaitu jabat tangan khas tanah pasundan. Selama prosesi ini, kedua pengantin melantunkan dengan gaya berpantun. Biasanya, pelantunan pantun ini dilakukan oleh sepasang juru sawer agar prosesi terlihat lebih menarik. Berikut adalah contoh pantun pada saat prosesi buka pintu. 


\section{Data (6) \\ Buka Pintu \\ (Sinom Degung)}

Pameget:

Laki-laki:

Assalamualaikum

Assalamualaikum

Panutan pupujan ati

teladan dan tambatan hati

Pangapunten torojangan

mohon maaf yang sebesar-besarnya

Dumeh tos pakait jangji

karena sudah terikat janji

\section{Isteri}

Isteri

Eta saha nu di luar

siapakah yang ada di luar?

Anu keketrok ti tadi

dari tadi mengetuk pintu

Asa taya tata pisan

seperti orang yang tak punya sopan santun

Hoyong geura terang sidik

ingin segera mengetahui

Mugi kersa mawarti

kabar apa yang dibawa

Sareng naon nu dimaksud

dan apa gerangan maksudnya

Pameget:

pihak lelaki

Goreng teuing bagja awak

jelek sekali keadaanku

Tiis pisan nasib diri

buruk sekali nasibku

Ku jungjungan ngalaman di saha-saha

Pan urang cik keneh pisan

kita baru saja mengucapkan akad

Ku saksi ku kadang wargi

disaksikan oleh para sanak keluarga

Geus rengse nya dirapalan

baru selesai mengucapkan akad

Engkang teh caroge

saya ini suamimu

Naha tataros deui mengapa bertanya lagi

Isteri:

Perempuan:

Hapunten anu kasuhun

mohon maaf

Sanes teu bade muka

bukannya tak mau membuka

Mung ku hoyong banget yakin

hanya ingin memastikan

Naha leres nu keketrok teh jungjungan

apakah betul suamiku yang mengetuk pintu

Abdi hoyong terang sidik

hanya ingin mengetahui

Mugi kersa ngawaleran

semoga bersedia memberi tahu

Mun leres teu ngabobodo

kalau memang benar dan tidak berbohong

Terangkeun naon ageman

apa yang digunakan

Keur ngamudi rumah tangga

untuk memimpin rumah tangga kita

Pameget:

pihak lelaki:

Taqwa nu Gusti nu Agung

takwa kepada Tuhan yang Maha Esa

Tah eta ageman tunggal

adalah cara yang akan digunakan

Pameget:

pihak lelaki:

Mun diwincik hiji-hiji

kalau dirici satu persatu

Jenglengan iman jeung ihsan

aku adalah iman dan ihsan

Iman teges takad hate

iman dengan tekad yang kuat

Ihsan hade laku lampah

tingkah laku dan perbuatan yang baik

Isteri:

Perempuan:

Leres geuning meni tetela

ternyata memang benar keinginan yang kuat

Paingan tos hoyong tepung

untuk bertemu dengan suami

Sihoreng sidik panutan 
orang yang akan menjadi teladan

Mung panuhun hiji deui

satu lagi permohonan

Pameget:

Suami:

Mangga geura sasuran

silakan segera bicara

Sangkan ulah hamham bae

jangan hanya diam

Isteri:

Isteri:

Teu seueur gaduh kahoyong

tidak banyak keinginanku

Pameget:

suami:

Geura pok engkang teu sabar

aku sudah tidak sabar

Isteri:

Isteri:

Samemeh mukakeun panto

sebelum pintu dibuka

Nya maos heula sahadat

tolong baca sahadat terlebih dahulu

Data (6) di atas merupakan bagian wacana yang dilantunkan pada rangkaian acara buka pintu dalam upacara pernikahan adat Sunda. Pantun dilantunkan oleh dua orang pengantin, yang diwakilkan kepada juru sawer, dengan berbalas pantun dan berbalas tanya. Keseluruhan tuturan dalam prosesi buka pintu ini dengan menggunakan bahasa Sunda. Dalam konteks sosiolinguistik, realitas lingual seperti ini memperlihatkan adanya sikap bahasa yang positif dan loyalitas bahasa yang sangat baik. Dua hal ini erat kaitannya dengan proses pemertahanan bahasa di lingkup tutur tertentu. Suatu bahasa dapat dikatakan bertahan apabila para penuturnya masih menampilkan sikap bahasa yang positif dan memiliki loyalitas berbahasa yang baik pula.

\section{Sungkem}

Sungkem dipahami sebagai salah satu prosesi dengan cara tunduk dan bersimpuh di hadapan orang tua. Sungkem dengan cara semacam ini menunjukkan bakti, permohonan maaf, dan permohonan doa restu seorang anak kepada kedua orang tuanya. Selain pasangan pengantin mengucapkan doa di dalam hati mereka, doa dan permohonan dalam sungkem akan dilantunkan oleh juru sawer. Berikut ini adalah contoh tuturan yang dilantunkan oleh juru sawer pada saat prosesi sungkem.

\section{Data (7)}

\section{Diucapkan kepada ibu}

Ibu, dinten ieu putra nyaluuh na pangkonan salira ibu,

Seja neda dihapunten,

Tina sugrining dosa sareng kalepatan putra.

Rumaos putra teh estuning teu weleh

Ngariweuhkeun sareng ngarepotkeun.

Ti wankgid dikandung salami salapan sasih,

Dirorok ti orok, ditimang ti bubudak tug dugi ka kiwari abdi sawawa,

Teu acan kantos abdi naur pamulang tarima, Bet teu ku hanteu kapegat ku pancen sanes.

Nanging mugia ibu wening galih ngalungsurkeun jiad pang dua rehna

Putra seja ngambah kahirupan rumah tangga, kalayan pidua

Sinareng restu ibu,

Putra nyuprih ka karidoan Illahi.

\section{Diucapkan kepada bapak}

Bapa, mugia ditampi semah sungkem putra, Dinten ieu putra nembrakeun panampian anu teu aya

Hinggana kana sagala rupi

Kadeudeuh sareng bimbingan bapa anu weleh ngatik ngadidik,

Ngaping siang sareng wengi, dugi ka kiwari putra nincak rarabi.

Mugi bapa ngajurung ku sih pidua, Putra singtinemu jatining bagja 
Enggoning ngambah sagara ka kahirupan rumah tangga

\section{Diucapkan kepada ibu mertua}

Ibu, ti wangkid dinten ieu putra seja nyiruruk dina kaweningan kalbu ibu.

Mugia ditampi lir putra pet ku hinis, Ulah dugi ka tumarumpang ngabimbing putra lir ka putra pituin.

Indit peutingna datang beurangna.

Putra neda panalingaan, Neda jiad pidua mugi putra tiasa nyubadanan sagala rupi pancen kahirupan

Anu sae mungguh Allah Subhanahu Wa Taala

\section{Diucapkan kepada bapak mertua}

Bapa, ieu putra nyanggakeun sembah sungkem tawis karumaosan

Sareng nampi kana sagala rupi kaweningan galih bapa,

Seja neda pangdeudeul sareng atikan

Dina enggoning, ngambah sagara rumah tangga,

Geusan ngahontal ka karidoan Allah Subhanahu wa Taala

Dugi katimu kabagjaan dunya rawuh aherat.

Dalam bahasa Indonesia:

\section{Diucapkan kepada ibu}

Ibu, hari ini putramu bersujud di pangkuan ibu Memohon agar diampuni,

Segala dosa dan kesalahan anakmu ini, Saya merasa sungguh sangat merepotkan

Sejak dikandung selama sembilan bulan

Dirawat dan dipelihara

Ditimang sejak bayi sampai menjadi dewasa

Belum pernah saya membalas

Mau tidak mau terhalang oleh tugas lainnya Mudah-mudahan dengan hati jernih memberikan doa dan restu

Karena anakmu ini akan mengarungi kehidupan rumah tangga

Dan mohon restu dari ibu, Serta mohon keridhoan dari Allah SWT.

\section{Diucapkan kepada bapak}

Bapak, semoga sembah sungkemku diterima Hari ini putramu menyerahkan kembali Apa yang telah diterima Kasih sayang bapak yang besar dan tak terhingga, membimbing dan mendidik, Mendampingi siang malam hingga hari ini sampai pada saatnya menikah, Semoga doa bapak mengiringi, Mendorong anakmu untuk menemukan kebahagiaan sejati

Dalam menempuh samudera kehidupan rumah tangga

\section{Diucapkan kepada ibu mertua}

Ibu, mulai hari ini anakmu masuk ke dalam keheningan kalbu, Semoga keinginan yang kuat dari putramu, Jangan sampai menghalangi bimbinganmu pada putramu ini,

Pergi malam datang siang

Semoga anakmu dapat bertanggung jawab akan segala rupa tugas kehidupan

Yang sesuai dengan aturan jalan yang ditentukan oleh Allah SWT

\section{Diucapkan kepada bapak mertua}

Bapak, anakmu menyampaikan sembah sungkem,

Dan menerima segala kemurahan hati bapak

Mau menerima rasa sayang dan juga ajaran dan pengalaman,

Dalam menjalani bahtera rumah tangga, Sampai mencapai keridhoan dan berkah dari Allah Sampai menemukan kebahagiaan dunia dan akhirat.

Data (7) di atas merupakan isi wacana dari sungkeman. Wacana tersebut dilantunkan oleh juru sawer dan ditujukan kepada kedua orang tua dari kedua pengantin yang melaksanakan pernikahan. Dalam konteks sosiolinguistik, realitas lingual yang ditampilkan oleh juru sawer pada rangkaian saweran tersebut telah 
menampilkan sikap bahasa yang positif. Sikap bahasa ini, pada masanya akan berjalan beriringan dengan loyalitas bahasa. Pelantunan doa dan restu tersebut seluruhnya menggunakan bahasa Sunda, tanpa ada campur kode dan alih kode dengan bahasa lainnya. Penggunaan bahasa Sunda dalam tuturan yang ada pada doa dalam rangkaian ngalepaskeun japati telah menampilkan adanya loyalitas berbahasa yang ditampilkan oleh juru sawer.

\section{Faktor Penyebab Pemertahanan Bahasa Sunda pada Upacara Pernikahan Adat Sunda di Kabupaten Bandung}

Realitas lingual di Indonesia telah memperlihatkan adanya gejala perubahan bahasa dari ekabahasawan menuju dwibahasawan dan multibahasawan. Oleh karena itu, perlu adanya sinergi antara bahasa Indonesia dengan bahasa daerah sebagai bahasa ibu. Bahasa Indonesia sebagai bahasa nasional yang dianggap sebagai bahasa $\mathrm{H}$ (high), bahasa yang dianggap memiliki prestise tinggi. Bahasa daerah yang dianggap sebagai bahasa L (low), bahasa yang dianggap memiliki prestise rendah. Namun demikian, dalam praktiknya, sinergi lingual yang ada pada dwibahasan tidak berjalan lancar dan tidak tuntas. Oleh karena itu, pembahasan tentang pemertahanan bahasa dari waktu ke waktu menarik untuk terus dikaji. Hal ini untuk menemukan pola baku dan upaya tersistematis untuk menempatkan bahasa yang ada secara pas dan proporsional. Perubahan bahasa karena adanya pergeseran akibat kontak dengan bahasa lain, khususnya bahasa yang dianggap memiliki prestise lebih tinggi $(H)$ tetapi selalu ada kecenderungan mempertahankan status quo, sebuah tren pemertahanan dalam perilaku berpola yang ada pada kelompok masyarakat tertentu (Bee, 1974).

Beberapa faktor pendorong dan penyebab terjadinya pemertahanan bahasa Sunda melalui upacara pernikahan adat Sunda di Kabupaten Bandung. Pertama, adanya keinginan agar tetap loyal dan setia dengan identitas kultural yang dimiliki oleh masyarakat Sunda. Kedua, latar belakang kultural keluarga yang melangsungkan upacara pernikahan.

\section{Mempertahankan Kultur}

Dalam konteks realitas lingual, praktik kultural yang ada di tengah-tengah masyarakat Sunda masih terlihat adanya upaya untuk menjunjung budaya Sunda sebagai upaya mempertahankan indentitas kulturalnya. Hal ini terlihat dari upacara pernikahan adat Sunda yang menggunakan bahasa Sunda sebagai ekspresi lingualnya. Bahasa merupakan bagian yang tidak terpisahkan dari budaya. Menjaga budaya berarti menjaga identitas kulturalnya. Dengan menjaga penggunaan bahasa Sunda sebagai media komunikasi di berbagai ranah komunikasi, dapat dijadikan sebagai indikator penjagaan identitas kultural oleh masyarakat pendukungnya.

Upaya pemertahanan dan regenerasi budaya lokal masih banyak terdapat pekerjaan rumah. Salah satunya adalah upaya dokumentasi oleh pihak terkait yang berkepentingan untuk menjaga dan melestarikan budaya Sunda. Oleh karena itu, mesti ada upaya serius dan tersistematis untuk mewujudkan adanya pemertahanan budaya dan bahasa di lingkungan Sunda.

Realitas lingual kelompok tutur tertentu di wilayah Sunda, masih menampilkan adanya sikap positif dan loyalitas berbahasa yang cukup baik. Hal itu terlihat dari praktik berbahasa pada sebagian besar ranah komunikasi yang ada. Salah satunya adalah pada upacara pernikahan adat Sunda di Kabupaten Bandung. Kondisi ini cukup bagus untuk mengembangkan bahasa dan budaya Sunda kepada masyarakat umum.

\section{Latar Belakang Geo-Kultural}

Faktor ini merupakan aspek ruang (spasial) yang melatarbelakangi adanya pemertahanan bahasa Sunda melalui upacara pernikahan adat Sunda. 
Aspek ini berkenaan dengan daerah tempat pelaksanaan upacara pernikahan dan latar belakang kultural keluarga yang melangsungkan upacara pernikahan tersebut. Maksudnya adalah, apabila latar belakang kultural dari keluarga yang melangsungkan pernikahan berasal dari suku Sunda, dapat dipastikan bahwa upacara pernikahan tersebut akan berlangsung dengan mengusung adat Sunda secara utuh atau sebagian besarnya. Apabila latar belakang kultural dari kedua keluarga yang melangsungkan pernikahan berasal dari suku yang berbeda, misalnya keluarga lelaki dari suku Jawa dan keluarga perempuan dari suku Sunda. Dalam kondisi demikian, akan ada dilema kultural yang dihadapi oleh kedua keluarga dalam penentuan konsep acara pernikahan yang akan dilangsungkan. Akhirnya akan diambil jalan tengah dari keduanya, yaitu dengan tidak mengusung adat tertentu atau bahkan mencampurkan kedua adat yang ada.

\section{SIMPULAN DAN SARAN}

\section{Simpulan}

Bentuk pemertahanan bahasa Sunda pada upacara pernikahan adat Sunda di Kabupaten Bandung, meliputi bentuk penjemputan oleh lengser, saweran inti, ngaleupaskeun japati, buka pintu, dan sungkem. Faktor yang menyebabkan terjadinya pemertahanan bahasa
Sunda pada upacara pernikahan adat Sunda di Kabupaten Bandung adalah mempertahankan kultural dan latar belakang kultural. Bahasa merupakan bagian yang tidak terpisahkan dari budaya. Menjaga bahasa berarti menjaga identitas kulturalnya. Dengan menjaga penggunaan bahasa Sunda sebagai media komunikasi di berbagai ranah komunikasi, dapat dijadikan sebagai indikator penjagaan identitas kultural oleh masyarakat pendukungnya.

\section{Saran}

Dari hasil yang diperoleh dalam penelitian ini, dapat dikemukakan bahwa masih banyak aspek yang dapat dikaji terhadap gejala dan bentuk pemertahanan bahasa Sunda serta menghubungkannya dengan aspek kebudayaan. Penelitian-penelitian serupa akan semakin memperkaya pengkajian bahasa, khususnya gejala pemertahanan bahasa dengan menghubungkannya dengan aspek kebudayaan dan kearifan lokal.

Penelitian serupa perlu dilakukan dengan melibatkan subjek penelitian dalam jumlah yang lebih banyak, sehingga diharapkan akan diperoleh hasil yang bisa berlaku secara luas. Dengan ketersediaan waktu yang cukup memadai; diharapkan dapat menghasilkan output dan outcome penelitian yang komprehensif.

\section{PUSTAKA ACUAN}

Aritonang, B. (2017). Bahasa Indonesia, daerah, dan asing di wilayah perbatasan: Studi pada Bahasa Waisa dan Muyu. Jurnal Pendidikan dan Kebudayaan, 2(2) 135-155.

Brata, N.T. (2010). Bahasa dan integrasi bangsa dalam kajian antropologi-fungsional. Jurnal Pendidikan dan Kebudayaan, 16(4) 469-476.

Duranti, A. (1997). Linguistic Anthropology. Los Angeles: University of Calofornia.

Dwimarwati, R. \& Wita, A. (2013). Sandiwara Sunda sebagai bentuk transmisi nilai bagi generasi muda. Panggung, Jurnal Seni Budaya, 23(3) 261-269.

Halliday, M.A.K. (1973). Exploration in The Functions of Language. London: Edward Arnold.

Mbete, A.M. (2015). Masalah kebahasaan dalam kerangka pelestariannya: perspektif ekolinguistik. Jurnal Tutur, 1(2) 181-188.

Muchtar, R.H.U. \& Ki Umbara. (1987). Modana. Bandung: PT Mangle Panglipur. 
Muhadjir, N. (2011). Metodologi penelitian: paradigma positivisme objektif, phenomenologi interpretatif, logika bahasa platonis, chomsky, hegelian, dan hermeneutik, paradigma studi islammatematik, recursion, set theory, structure equality modeling dan mix. Yogyakarta: Rakesarasin.

Pastika, I.W. (2012). Pengaruh bahasa asing terhadap bahasa indonesia dan bahasa daerah: peluang atau ancaman. Jurnal Kajian Bali, 02(2) 142-164.

Poedjosoedarmo, S. (2017). Language Propriety in Javanese. Journal of Language and Literatur, 17(1) 1-9.

Purnomowulan, N.R., Samson CMS, Machdalena, S., Dewi, E.R., Endrawan, A. (2017). Teknologi tepat guna - membangun kecintaan dan kebanggaan pada kearifan lokal bahasa Sunda. Panggung, Jurnal Seni Budaya, 27(1) 62-73.

Rokhman, F. (2013). Sosiolinguistik: Suatu pendekatan pembelajaran bahasa dalam masyarakat multikultural. Tangerang: Graha Ilmu.

Spradley, J.P. (2016). The Ethnographic Interview. Ellinois: Waveland Press Inc.

Sudaryanto. (2015). Metode dan Aneka Teknik Analisis Bahasa: Pengantar Penelitian Wahana Kebudayaan secara Linguistis. Jakarta: Diandra Primamitra. 